\title{
$\mathrm{SDS}-\mathrm{TWR}$ 기반의 거리측정 정확도를 위한 IEEE 802.15.4a 소프트웨어 스택 구현 ${ }^{\dagger}$
}

\section{(Implementation of IEEE 802.15.4a Software Stack for Ranging Accuracy Based on SDS-TWR)}

\author{
유 준 혁*, 김 희 철** \\ (Joonhyuk Yoo and Hiecheol Kim)
}

\begin{abstract}
요 약 거리측정(Ranging-based) 기반 무선측위 알고리즘을 활용하는 무선 네트워크 환경에 서 위치추적의 정확도는 노드들 간의 거리측정의 정확도에 크게 좌우된다. 저전력 무선 네트워크 환경에서 거리측정 기반 무선측위의 실용화를 위해서는 하드웨어에서 제공하는 거리측정 정확도 를 훼손시키지 않고 그대로 유지할 수 있는 안정된 HAL(Hardware Abstraction Layer)과 MAC(Medium Access Layer) 소프트웨어의 구현이 요구된다. 본 연구에서는 IEEE 802.15.4a를 지원하는 RF 칩인 나노트론(Nanotron)사의 NA5TR1를 기반으로 한 센서노드를 제작한 후 이 노드에 탑재될 IEEE $802.15 .4 \mathrm{a}$ 소프트웨어 스택의 기본적인 기능을 설계-구현하였다. 소프트웨 어 스택은 나노트론 사의 SDS-TWR 기법의 일반모드를 거리측정 알고리즘으로 채택-지원하고 있다. 개발된 센서노드를 활용해 테스트 네트워크를 구축한 후 노드간의 실 환경에서 실시간 거 리측정의 정확도를 평가한 결과 SDS-TWR의 일반모드에서 평균 거리측정 오류율은 $24.2 \%$ 인 것 으로 나타났다.
\end{abstract}

\section{핵심주제어 : IEEE 802.15.4a, 거리측정 기반 무선측위, 매체접근제어}

Abstract The localization accuracy in wireless sensor networks using ranging-based localization algorithms is greatly influenced by the ranging accuracy. Software implementation of HAL(Hardware Abstraction Layer) and MAC(Medium Access Layer) should seamlessly deliver the raw performance of ranging-based localization provided by hardware capability fully to the applications without degrading the raw performance. This paper presents the design and implementation of the software stack for IEEE 802.15.4a which supports normal ranging mode of the Nanotron's NA5TR1 RF chip. The experiment results shows that average ranging error rate with our implementation is $24.5 \%$ for the normal mode of the SDS-TWR ranging scheme.

Key Words : IEEE 802.15.4a, Ranging-based Wireless Localization, MAC Layer

\footnotetext{
$†$ 본 연구는 산업통상자원부 및 한국산업기술평가관리원의 산 업융합원천기술개발사업[(정보통신)10041145, 자율군집을 지 원하는 웰빙형 정보기기 내장 소프트웨어 플랫폼 개발]의 일환으로 수행되었음

* 대구대학교 임베디드시스템공학과, 제1저자

** 대구대학교 임베디드시스템공학과, 교신저자 (e-mail : hckim@daegu.ac.kr)
} 


\section{1. 서 론}

최근 들어 무선센서네트워크(Wireless Sensor Network)의 실환경에서의 활용이 크게 늘고 있다. 응 용영역은 환경분야에서 군사분야에 이르기까지 점차 다양해지고 있다. 이러한 $\mathrm{WSN}$ 은 센서노드가 배치된 필드로부터 지속적으로 원하는 환경을 수집하고 제어 할 수 있는 수단을 제공하며, 특히 오지, 화산, 교전지 역 등 사람이 접근하기 어려운 위치에 센서노드를 배 치할 경우에 원격에서 지속적으로 해당 지역의 정보 를 취득하는 것을 가능하게 한다. 대부분의 응용은 주 위 환경정보를 취득하여 저전력 무선전송을 통해 사 물의 모니터링과 제어를 수행하는 형태이지만, 최근에 는 센서노드의 위치정보와 환경 정보를 결합하여 높 은 부가가치를 창출할 수 있는 응용 서비스도 주목을 받고 있다. 이러한 위치정보를 활용할 수 있는 분야는 주차관리, 물류자동추적, 미아방지, 안전관리, 보안감시 등 매우 다양하다[1,2].

저전력 무선 네트워크 환경에서 위치정보를 활용하 기 위해서는 노드들의 위치를 인식할 수 있는 무선측 위 기술이 요구된다[3]. 일반적으로 측위방식에 거리를 사용하는 거리기반(Range-based) 측위기술에서 보다 정확한 측위가 가능하려면, 우수한 측위 알고리즘과 함께 거리측정의 정확도 확보도 필수적으로 요구된다. IEEE 802.15.4a CSS(Chirp Spread Spectrum)와 관련 한 기존 연구들은 주로 무선측위 알고리즘에 연구의 초점을 두었으며, 무선측위의 오류방지 및 정밀도 향 상에 크게 기여하고 있다[4,5]. 반면에, 거리측정의 정 확도에 대해서는 체계적인 연구가 상대적으로 부족한 상황이며, 특히 실 환경에서의 구현 및 성능평가는 거 의 이루어지고 있지 않은 상태이다.

이 연구는 IEEE $802.15 .4 \mathrm{a} / \mathrm{CSS}$ 의 거리측정의 정확 도를 주제로 다룬다. 연구의 목적은 $\mathrm{WSN}$ 환경의 저 전력 센서노드들이 IEEE $802.15 .4 \mathrm{a} / \mathrm{CSS}$ 기반으로 보 다 정확한 거리측정 기능을 가질 수 있도록 구현하는 데 있다. 연구내용은 크게 세 부분으로 구성된다. 첫 째, IEEE 802.15.4a/CSS를 지원하는 센서노드를 제작 한다. 센서노드의 $\mathrm{RF}$ 칩으로는 현재 기술적으로 가장 앞서 있으며 산업계에서 가장 많이 활용되고 있는 나 노트론(Nanotron)사의 NA5TR1을 사용한다[6]. 둘째, 제작한 센서노드에 탑재될 IEEE 802.15.4a MAC(Medium Access Layer) 소프트웨어 스택을 개
발한다. 이 소프트웨어 스택은 IEEE 802.15.4a 표준에 의거해서 일반 $\mathrm{MAC}$ 기능과 위치측정 기능, $\mathrm{RF}$ 칩을 위한 HAL(Hardware Abstraction Layer)로 구성된다. 마지막으로 개발된 IEEE 802.15.4a 소프트웨어 스택을 탑재한 센서노드를 활용해 테스트 네트워크를 구축한 후 IEEE $802.15 .4 \mathrm{a}$ 의 $\mathrm{RF}$ 칩의 하드웨어에서 제공하는 실시간 거리측정의 정확도가 실 환경에서도 최대한 활용될 수 있는지를 실험하였다.

이 논문의 나머지 부분은 다음과 같이 구성된다. 2 장은 본 연구에서 채택하고 있는 거리측정을 지원하 는 $\mathrm{RF}$ 칩인 NA5TR1과 거리측정 기법인 $\mathrm{SDS}-$ TWR(Symmetrical Double-Sided Two-Way Ranging) 기반의 거리측정 기법을 간략히 설명한다. 3장에서는 본 연구에서 수행한 IEEE 802.15.4a 표준을 지원하는 스택 소프트웨어의 설계 및 구현 내용을 설명한다. 4 장에서는 본 연구에서 구현한 소프트웨어 스택의 거 리측정 정확도를 평가하기 위한 실험환경과 평가방법, 그리고 성능평가 결과를 설명한다. 마지막으로 5장에 서는 이 연구의 결론을 짓고 향후 연구내용을 제시한 다.

\section{SDS-TWR 거리측정 기법}

SDS-TWR(Symmetrical Double-Sided Two- Way Ranging)은 NA5TR1 RF칩을 장착한 센서노드 상에 서의 거리측정을 위해 나노트론 사에서 개발한 거리 측정 기법이다. SDS-TWR 방법은 두 노드 간에 서로 한번씩 DATA 프레임과 하드웨어 ACK 프레임을 주 고받는 두 개의 라운드로 구성되며, 이 과정에서 측정 된 시간 값을 이용해 거리를 계산한다. 이 두 노드를 각각 로컬노드(Local Node)와 원격노드(Remote Node) 라고 정의한다. 측정하는 시간은 두 가지로 구성되는 데 하나는 전송지연시간(TX Propagation Delay)으로 로컬노드가 거리측정 대상인 원격노드에게 DATA 프 레임을 전송한 시점부터 원격노드로부터 $\mathrm{ACK}$ 프레임 을 수신할 때까지의 지연시간을 말한다. 다른 하나는 프레임처리 지연시간(Frame Processing Delay)으로 원격노드가 DATA 프레임을 수신한 시점부터 하드웨 어 $\mathrm{ACK}$ 프레임을 생성하여 로컬노드에게 전송할 때 까지의 지연시간을 의미한다. 이 두 값은 두 노드 사 이의 거리 계산을 가능하게 한다. 
<그림 1>은 SDS_TWR의 일반모드에서의 거리 측 정방식을 도시화하고 있다. 측정대상 시간은 4 가지로 $T_{1}$ 은 로컬 노드가 원격노드로 DATA 패킷을 전송한 시점부터 원격노드로부터 하드웨어 ACK 패킷을 수신 하기까지 전송지연시간을 나타내다. $T_{2}$ 는 원격노드가 로컬 노드로부터 DATA 패킷을 수신하고 하드웨어 $\mathrm{ACK}$ 패킷전송을 개시하는 시점까지의 처리지연시간 이다. $T_{3}$ 는 원격노드가 로컬노드로 DATA 패킷을 전

$$
\text { 거리 }=\frac{\left(T_{1}-T_{2}\right)+\left(T_{3}-T_{4}\right)}{4} \times 3 \times 10^{8}
$$

\section{3. 소프트웨어 모듈 구현}

이 장에서는 본 연구에서 수행한 IEEE 802.15.4a 표 준을 지원하는 스택 소프트웨어의 설계와 구현을 설

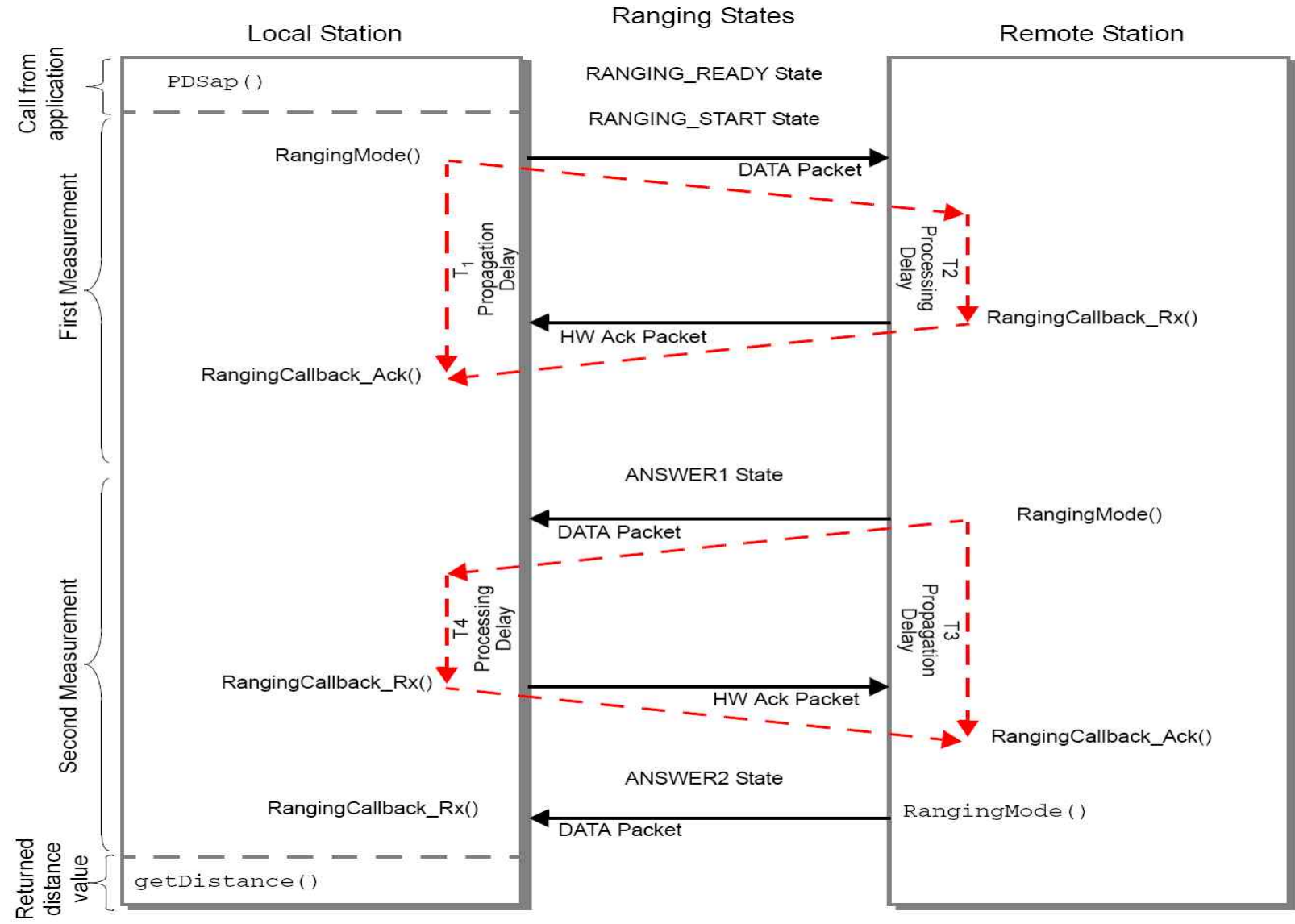

<그림 1> SDS-TWR의 일반모드 동작

송한 시점부터 로컬노드로부터 하드웨어 $\mathrm{ACK}$ 패킷을 수신하는 시점까지의 전송지연시간을 말하며, $T_{4}$ 는 로컬노드가 원격노드로부터 DATA 패킷을 수신하고 하드웨어 $\mathrm{ACK}$ 패킷을 전송하기까지 처리지연시간이 다. 이 기법에서 모두 4차례의 패킷 전송이 이루어지 므로 거리는 아래와 같이 계산된다.
명한다. 이 소프트웨어 스택은 크게 네 개의 모듈로 구성된다. 첫 번째 모듈은 NA5TR1 Radio HAL (Hardware Abstraction Layer)로서 NA5TR1 RF 칩 의 제어를 위한 디바이스 드라이버에 해당한다. 두 번 째 모듈은 IEEE 802.15.4a의 PHY 계층을 구현하고 있다. 이 모듈은 상위 $\mathrm{MAC}$ 에서 요청받은 프레임을 전송하거나 $\mathrm{PHY}$ 계층에서 제공하는 관리기능에 대한 $\mathrm{API}$ 를 제공한다. 세 번째 모듈은 IEEE 802.15.4a의 일 
반 $\mathrm{MAC}$ 계층의 기능을 구현하고 있다. 이 모듈은 $\mathrm{MAC}$ 계층의 데이터 전송과 관리 기능으로 구성된다. 마지막은 거리측정 모듈로서 $\mathrm{MAC}$ 계층에 위치하며, SDS-TWR 기법을 이용한 거리측정 기법을 지원한다.

\subsection{NA5TR1 Radio HAL 모듈}

NA5TR1 Radio HAL의 구현은 두 가지 특징을 지 니고 있다. 첫째, 이 모듈은 802.15.4a PHY 계층에서 요구되는 기능과 함께 거리측정 관련 추가 $\mathrm{API}$ 를 포 함하고 있다. 둘째, 이 모듈은 NA5TR1에서 제공하는 두 전송모드인 자동모드(Auto Mode)와 투명모드 (Transparent Mode)를 모두 지원한다. 따라서 상위 $\mathrm{IEEE} \mathrm{802.15.4a} \mathrm{MAC} \mathrm{계층은} \mathrm{필요에} \mathrm{따라} \mathrm{각} \mathrm{모드를}$ 선택해 사용할 수 있다.

NA5TR1 Radio HAL모듈은 크게 RF 모듈 관리, $\mathrm{MCU}$ 인터페이스, ranging 지원의 3개 세부모듈로 구 성된다. 첫째, $\mathrm{RF}$ 모듈 관리 세부모듈은 상위 계층에 하드웨어 제어 및 패킷 송수신 관련 $\mathrm{API}$ 를 제공한다. 이를 위해, 이 세부모듈은 NA5TR1 하드웨어 초기화, 주소 설정, 그리고 패킷 송-수신 기능을 제공한다. NA5TR1 하드웨어 초기화는 디바이스 리셋, 채널 주 소 등의 기본정보의 초기화, FDMA, 대역폭 등의 동 작 모드 초기화 등을 다룬다. 주소 설정 기능은 일반 $\mathrm{RADIO}$ 칩과 같이 $\mathrm{IEEE}$ 802.15.4 주소체계의 $\mathrm{PANID}$ 와 ShortAddress를 설정할 수 있는 기능을 제공한다. 한편, 패킷 송수신 기능으로는 패킷 송수신 관련 레지 스터를 설정할 수 있는 기능과 패킷의 $\mathrm{RF}$ 송수신 기 능이 있다.

둘째, $\mathrm{MCU}$ 인터페이스 모듈은 SPI 통신을 이용하 여 NA5TR1 하드웨어 내의 레지스터 및 세부 사양을 설정하거나 NA5TR1 모듈 내부의 RAM 영역에 데이 터를 읽고 쓸 수 있는 $\mathrm{API}$ 를 제공한다. 마지막으로 ranging 지원 모듈은 거리특정을 위한 패킷의 송신과 수신을 위한 $\mathrm{API}$ 를 제공한다. 패킷 송신과 관련해서 는 거리측정 목적지와 상태의 설정, 데이터 기록 등의 기능이 있다. 패킷 수신과 관련해서는 수신 패킷의 유 효성을 확인하거나, 수신 패킷에 대한 시간을 기록하 는 기능이 있다. <표 1>은 NA5TR1 Radio HAL 모 듈이 상위에 제공하는 주요 $\mathrm{API}$ 함수의 목록을 보여 준다.
<표 1> HAL 모듈의 주요 API 함수

\begin{tabular}{|c|c|}
\hline API & 설명 \\
\hline request_radio_status() & - 현재 상태 얻음 \\
\hline set_pan_coordinator() & $\begin{array}{l}\text { - 코디네이터로 설정 (NA5TR1 } \\
\text { 에서는 이 기능이 지원되지 않음) }\end{array}$ \\
\hline set_radio_addr() & $\begin{array}{l}\text { - 디바이스 주소(short, ieee, pan) } \\
\text { 설정 }\end{array}$ \\
\hline get_radio_info() & - 디바이스 정보 추출 \\
\hline $\begin{array}{l}\text { change_radio_trans_pow } \\
\text { er() }\end{array}$ & - 디아비스 Tx 파워 설정 \\
\hline change_radio_channel() & - 디바이스 채널 변경 \\
\hline disable_radio_tranc() & - 디바이스 송/수신 중지 \\
\hline change_radio_state() & - 디바이스 상태 변경 \\
\hline write_radio_txfifo() & $\begin{array}{l}\text { - 송신을 위한 데이터를 TX RAM에 } \\
\text { 씀 }\end{array}$ \\
\hline
\end{tabular}

\subsection{IEEE 802.15.4a PHY 모듈}

IEEE 802.15.4a PHY 계층은 프레임을 RF 채널에 전송하는데 $\mathrm{MAC}$ 계층과 Radio $\mathrm{HAL}$ 사이에 위치한 다. PHY 계증의 구현은 다음과 같은 방향으로 진행하 였다. NA5TR1 RF 칩이 IEEE 802.15.4a 표준에서 요 구하는 기능들을 일부 제공하지 않는 점을 고려하며 표준가의 불일치를 최소화할 수 있도록 하였다. 아울 러, 프리머티브(Primitive)의 입력 파라미터 중에서 $\mathrm{UWB}$ 와 관련한 파라미터들의 지원이 필요하지 않으 므로 그와 관련된 사항은 구현에 반영하지 않았다. 개발 방식으로는 본 저자들이 소속한 연구소에서 기 개발하여 확보하고 있는 IEEE 802.15.4 PHY 모듈에 $\mathrm{CSS}$ 방식의 $\mathrm{RF}$ 칩 사용을 위해 필요한 사항만을 변경 하였다.

구현된 모듈은 상위 $\mathrm{MAC}$ 에 제공하는 기능에 있어 서는 일반 802.15.4 2006 표준과 동일한 사양을 갖는 다. 802.15.4a PHY는 데이터 전송을 위한 $\mathrm{PD}^{-}$ $\mathrm{SAP}$ (Phsical Layer Data Service Access Point)와 관 리과 관련된 PLME-SAP(Physical Layer Management Entity Service Access Point)으로 구성된다. PLME$\mathrm{SAP}$ 에서 제공하는 서비스들은 $\mathrm{CCA}$ (Clear Channel Assessment) 요청과 $\mathrm{ED}$ (Energy Detection) 측정 요 청, 물리 계층 $\mathrm{PIB}$ 속성에 대한 정보를 읽기 및 쓰기 요청, 송수신 트랜시버의 동작 상태 변경 등 기존 IEEE 802.15.4 PHY의 관리기능을 그대로 지원한다. PHY Layer와 관련된 관리 데이터들의 데이터베이스 인 $\mathrm{PIB}(\mathrm{PAN}$ Information Base)를 유지 관리된다. 


\subsection{IEEE 802.15.4a MAC 모듈}

IEEE 802.15.4a 표준을 기반으로 하는 MAC 모듈 개발에는 표준과의 부합성을 최대화하면서 구현의 복 잡성을 경감시키기 위해 다음과 같은 설계방향을 취 하고 있다. 첫째, $\mathrm{MAC}$ 모듈의 교체에 의해 기 개발된 상위 네트워크 계층에 영향을 주지 않도록 프리미티 브의 프로토타입을 IEEE 802.15.4(2006) 표준에 부합 되도록 변경하였다. 둘째, 표준에서 정의하고 있지 않 는 거리측정(Ranging) 기능은 표준과의 이질성을 최 소화하기 위해 IEEE 802.15.4a 일반 MAC 모듈과 분 리하여 독립적인 모듈로 구현하였다. 셋째, 구현 복잡
등과 같은 기존 $\mathrm{RF}$ 모듈에서 제공하는 $\mathrm{SACK}$ 나 $\mathrm{SACKPEND}$ 와 같은 명령 스트로브를 제공하지 않기 때문에 $\mathrm{ACK}$ 프레임 생성 및 전송 기능은 하드웨어 기능을 사용하는 대신 소프트웨어적로 구현된다. 둘째, NA5TR1 라디오 드라이버를 투명모드(Transparent Mode)로 동작 시키는 경우 수신 프레임의 오류를 검 출은 $\mathrm{MAC}$ 계층에서 직접 수행해야 하기 때문에 $\mathrm{CRC}$ (Cyclic Redundancy Check)기능을 $\mathrm{MAC}$ 모듈에 구현하였다. $\mathrm{MAC}$ 모듈에서 $\mathrm{PHY}$ 계층으로 $\mathrm{MPDU}$ 전달하는 시점에서 마지막 2byte에 $\mathrm{FCS}$ (Frame Check Sequence)를 붙여 전달하게 된다. 마지막으로 $\mathrm{MAC}$ 모듈의 CSMA-CA 기능이 제거되었다.

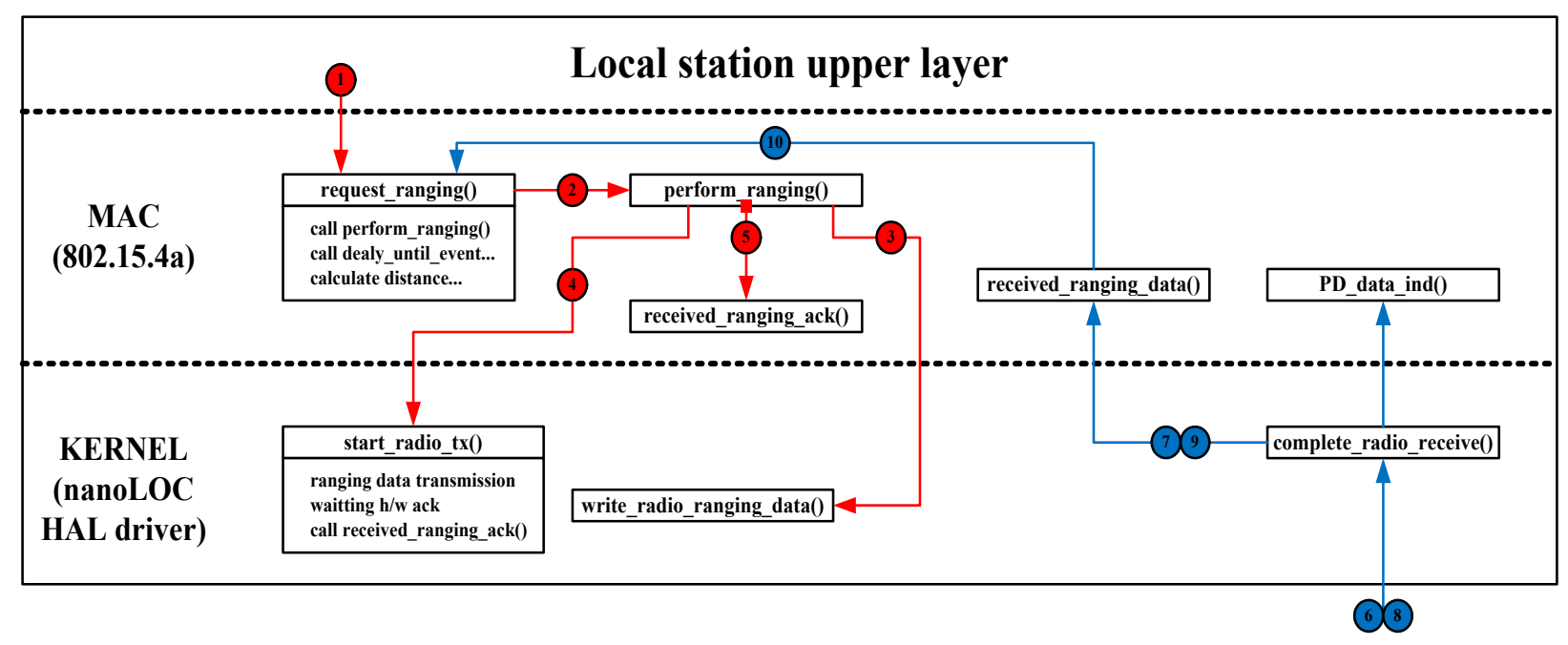

<그림 2> Local Station Ranging 동작 흐름

성을 경감시키기 위해 모듈은 IEEE 802.15.4a의 비콘 모드(Beacon-enabled Mode)와 논비콘모드(Non-beacon Mode) 중에서 논비콘 모드만을 지원하도록 하였 다.

위 구현 방향에 의거해 802.15.4a MAC 모듈의 현 버전은 일반적인 직접전송, 네트워크 가입, 스캔 기능, MAC-PIB 액세스 등의 기능은 지원하지만 비콘 모드 와 관련되거나 흔히 사용되지 않는 GTS, 간법전송모 드, 네트워크 탈퇴, 동기화 관련 Primitive는 지원하지 않고 있다.

한편, 이 모듈의 구현에 있어 NA5TR1 Radio 칩과 관련된 특화된 사항으로 $\mathrm{ACK}$ 프레임 처리, 프레임에 대한 $\mathrm{CRC}$ (Cyclic Redundancy Code) 생성 및 확인, CSMA-CA 기능이 있다. 먼저, NA5TR1는 CC2420
NA5TR1 HAL은 CCA(Channel Clear Assessment) 수행이나 결과를 확인하는 방법을 제공하지 않기 때 문에 상위 계층에서 CSMA-CA 알고리즘의 구현이 어렵다. 프레임 전송시 NA5TR1에서 Chirp Symbol 검출을 하드웨어적 수행하고, 백오프 등의 기능을 레 지스터 설정을 통해 지정할 수 있기 때문에 채널 접 근에 대한 절차는 $\mathrm{HAL}$ 드라이버에서 처리된다.

\subsection{SDS-TWR 기법을 이용한 거리측정 모듈}

IEEE 802.15.4a 표준에서 데이터 전송은 CSS 방식 만을 사용하지만, 거리측정 관련 기능은 $\mathrm{CSS}$ 와 UWB 방식을 모두 사용할 수 있도록 규정하고 있다. NA5TR1 칩의 경우에는 CSS 방식만을 지원하고 있 
어 본 거리 측정 모듈은 CSS 방식의 SDS-TWR 기 법을 구현한다. 이 모듈은 IEEE 802.15.4a 모듈과 독 립적으로 사용이 가능하도록 구현되었다. SDS-TWR 거리측정 기법의 두 가지 모드, 즉 일반모드와 신속모 드 중에서 일반모드만을 지원한다. NA5TR1 라디오 칩에서는 제공하는 자동모드와 투명모드 또한 모두 지원하고, 나노트론사에서 정의한 패킷 타입도 모두 지원한다.

거리 측정 모듈의 구현 내용을 SDS-TWR의 일반 모드를 중심으로 간략히 설명한다. 거리 측정모듈은 상위 계층에 거리측정 동작전체 로직을 포함하고 있 는 한 개의 $\mathrm{API}$ 를 제공한다. 이 API는 request_rang$\operatorname{ing}()$ 함수로서 상위 계층으로부터 거리측정 요청을 받아 지정된 노드의 거리 값을 반환한다. <그림 2> 는 로컬노드, 즉 거리측정을 시작하는 노드, 측에서 이 함수의 호출로 일반모드의 거리측정이 이루어지는 과 정을 개괄적으로 보여준다. 원격노드 측에서의 동작 과정은 로컬노드의 동작과정과 거의 유사하므로 그 내용은 별로도 나타내지 않았다. request_ranging() 함 수는 SDS-TWR 기법의 일반모드를 구성하는 두 라 운드를 상태전이(State-transition) 로직으로 구현하고 있다. perform_ranging()을 호출하면, 첫 번째 라운드 를 시작하여 전송할 데이터 패킷을 $\mathrm{HAL} \mathrm{API를} \mathrm{통해}$ $\mathrm{RF}$ 칩의 버퍼에 기록한 후 거리측정 대상노드에게 거 리측정 데이터 패킷을 전송하며, 해당 $\mathrm{ACK}$ 패킷을 수신하는 기능을 수행한다. 이 과정을 마치면 내부의 received_ranging_data() 함수를 통해 거리측정 패킷 송수신과 관련된 측정값을 저장하고 이어지는 거리측 정 상태를 지정한다. 이후 두 번째 라운드를 진행하는 데 이는 거리측정 상대노드로부터 데이터 패킷을 수 신한 후 $\mathrm{ACK}$ 를 전송하는 과정으로 구성된다. 참고로, 그림에서 왼편은 첫 번째 라운드를, 오른편은 두 번째 라운드를 나타낸다. request_ranging()에서는 이 두 라 운드를 마치면 측정시각 값들을 활용하여 거리계산을 수행하며 최종결과는 함수의 반환 값으로 내보낸다.

\section{4. 실험 및 평가}

이 장에서는 $802.15 .4 \mathrm{a}$ 소프트웨어 스택의 거리측정 기능의 성능을 평가하기 위한 실험환경과 평가방법, 그리고 성능평가 결과를 설명한다.
거리측정을 위한 실험을 위하여 앞 절에서 설명한 IEEE 802.15.4a 소프트웨어 스택이 탑재된 노드들로 노드간의 일대일 거리측정을 위한 실험 네트워크를 구축하였다. <그림 3>은 실험 네트워크의 구성을 보 여준다. 이 네트워크는 간략히 $\mathrm{WDMN}$ (Weaver Distance Measurement Network)라고 정의한다.

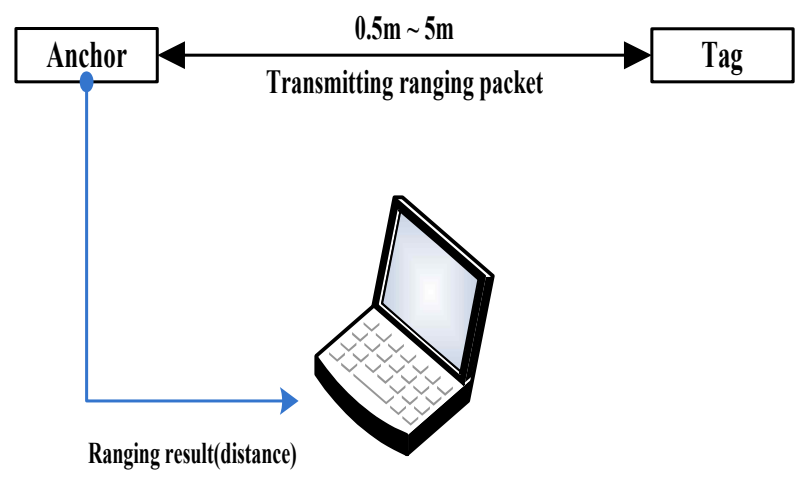

<그림 3> 실험 구성도

실험 네트워크는 건물 내에 설치되며, 2 개의 센서노 드와 한 개의 $\mathrm{PC}$ 로 구성된다. 센서노드들 중에서 한 개는 앵커노드(Anchor Node, Ranging Master)로 다 른 한 개는 태그노드(Tag Node, Ranging Slave)로서 역할을 갖는다. 앵커노드는 태그노드에 패킷을 전송하 여 자신과 태그노드 간의 거리측정을 수행하는 역할 을 갖는다. 태그노드는 단순히 거리측정 요청이 오면 아전 절에서 설명한 바와 같이 수동적으로 해당 절차 를 수행하게 된다. 앵커노드에 시리얼케이블을 연결되 는 $\mathrm{PC}$ 는 단순히 앵커노드로부터의 실험결과 로그를 시리얼 통신(UART)을 통해 수집하는 역할을 갖는다. 앵커노드와 태그노드 간의 $\mathrm{RF}$ 통신을 위한 주파수는 $2.4 \mathrm{GHz}$ ISM 밴드를 사용하며, 아울러 채널과 주파수 대역폭은 각각 0 번과 $80 \mathrm{MHz}$ 가 사용된다. $\mathrm{RF}$ 전송 파 워는 $10 \mathrm{dBm}$ 으로 설정된다.

$\mathrm{WDMN}$ 실험환경의 센서노드에 탑재되는 소프트웨 어는 IEEE 802.15.4a 스택 소프트웨어, 네트워크 모듈, 애플리케이션 모듈로 구성된다. IEEE 802.15.4a 소프 트웨어는 앞에서 이 논문에서 개발한 것으로 이미 앞 절에서 충분히 설명했다. 네트워크 모듈은 네트워크 자율구성 및 동적 메시 토폴로지 기반 라우팅 기능을 지원하고 있지만, 이 실험에서는 기본적으로 두 개의 노드간의 PAN 네트워크를 자동으로 구성하는 것 이 
외에는 다른 기능은 사용되지 않는다. 한편, 네트워크 계층 상위의 애플리케이션 공간에서 태그노드를 위해 서는 특별히 취해야 할 동작이 없어 응용 애플리케이 션은 주로 앵커노드을 위한 기능만을 지니고 있다. 응 용 애플리케이션은 802.15.4a MAC에 포함되어 있는 ranging module이 제공하는 API(request_ranging())를 호출한 여 지정한 $\mathrm{Tag}$ 와의 거리 원시정보를 측정한 후 거리를 계산하고, RS-232를 통해서 거리 값 모니 터링 $\mathrm{PC}$ 에 출력한다.

실험은 노드 간의 거리와 측정모드를 변경해 가며 거리측정을 수행하였다. 실험에 사용된 측정대상거리 는 그 범위가 $0.5 \mathrm{~m} \sim 5 \mathrm{~m}$ 이며, 측정대상 거리는 $0.5 \mathrm{~m}$ 를 포함하고 $1 \mathrm{~m}$ 부터 $5 \mathrm{~m}$ 까지는 각 $1 \mathrm{~m}$ 단위로 증가시 켜 테스트한다. 측정대상거리에 따라 모두 6 가지의 실험이 수행되며, 각 실험은 모두 동일한 방법으로 진 행되었다. 각 실험에서는 앵커노드는 태그에 대해 연 속적으로 거리측정 트랜잭션을 수행한다. 앵커노드는 태그에 대해 연속적인 1000 회의 성공적인 거리측정 트랜잭션을 수행하게 되면 해당 실험을 마친다. 앵커 노드와 태그간의 프레임 송수신 오류 등으로 정상적 인 거리측정 결과를 얻지 못할 경우에는 해당 거리측 정 트랜잭션은 제외되며, 앵커노드는 성공적인 트랜잭 션마다 시리얼 통신(UART)를 통해서 $\mathrm{PC}$ 에 그 결과 를 전달하여 최종 결과가 $\mathrm{PC}$ 에서 집계될 수 있도록 한다.

이 논문은 실제 산업환경에서 부족한 거리측정의 실 증자료를 제공하기 위해 평균 오차율과 최대 최소 오 차를 함께 측정한다. 거리측정 값의 단위는 소수점 아 래 2 자리 $(\mathrm{cm})$ 까지이며, 1000 개의 측정거리 값에 대 해 최소값, 최대값을 추출하여 살펴보고, 전체 평균값 을 계산하였다. 아울러 각 거리별 실험에서 최소 오차,

<표 2> 일반모드의 평균 오차율

\begin{tabular}{|c|c|c|c|c|c|c|c|}
\hline $\begin{array}{l}\text { 실 제 } \\
\text { 거리 } \\
(\mathrm{m})\end{array}$ & $\begin{array}{l}\text { 최소 } \\
\text { 값 }(\mathrm{m})\end{array}$ & 값 $(\mathrm{m})$ & $\begin{array}{c}\text { 평균 } \\
\text { 값 } \\
(\mathrm{m})\end{array}$ & $\begin{array}{l}\text { 최소 } \\
\text { 오차 } \\
\text { (m) }\end{array}$ & $\begin{array}{l}\text { 최대 } \\
\text { 오차 } \\
\text { (m) }\end{array}$ & $\begin{array}{c}\text { 평균 오 } \\
\text { 차 }(\mathrm{m})\end{array}$ & $\begin{array}{c}\text { 오차율 } \\
(\%)\end{array}$ \\
\hline 0.5 & 0.32 & 0.93 & 0.647 & 0 & 0.43 & 0.15366 & 30.7 \\
\hline 1 & 1.47 & 1.94 & 1.719 & 0.47 & 0.94 & 0.71873 & 71.9 \\
\hline 2 & 2 & 2.55 & 2.152 & 0 & 0.55 & 0.15243 & 7.6 \\
\hline 3 & 3 & 3.99 & 3.527 & 0 & 0.99 & 0.52732 & 17.6 \\
\hline 4 & 1.56 & 5.53 & 4.238 & 0 & 2.44 & 0.25103 & 6.3 \\
\hline 5 & 2.38 & 8.4 & 5.57 & 0.32 & 3.4 & 0.58225 & 11.6 \\
\hline \multicolumn{7}{|c|}{ 전체 평 } & 24.28 \\
\hline
\end{tabular}

최대 오차, 평균 오차, 평균 오차율을 계산하였다. 오 차는 측정치에서 실제거리를 뺀 값의 절대값이며 오차 율은 오차를 실제거리로 나누어 퍼센트로 나타낸다.

<표 2>는 구현된 소프트웨어 스택을 사용한 일반 모드에서의 거리측정 측정결과를 보여준다. 전체 6 가 지 실험에 대한 평균 오차율은 $24.3 \%$ 로 나타났고 있 다. 한편 아주 가까운 거리에서는 거리측정의 오차가 상대적으로 크다는 점을 발견할 수 있다. $1 \mathrm{~m}$ 이하와 $1 \mathrm{~m}$ 초과를 비교해 보면 이를 보다 정확하게 파악할 수 있다. $1 \mathrm{~m}$ 이하, 즉 $0.5 \mathrm{~m}$ 와 $1 \mathrm{~m}$ 거리에 대한 평균오 차율은 $51.3 \%$ 로 $1 \mathrm{~m}$ 초과의 평균오차율인 $10.8 \%$ 의 약 4.8 배로 나타나고 있다.

\section{5. 결론 및 향후 연구}

본 논문은 저전력 무선 네트워크 환경에서 노드들 의 무선측위 기술의 정확도 제고를 필요한 선결과제 인 거리측정 문제를 다룬다. 거리측정의 정확도를 제 고하기 위해 본 연구개발에서 수행한 연구내용은 크 게 세 가지로 요약된다. 첫째, IEEE 802.15.4a/CSS를 지원하는 $\mathrm{RF}$ 칩의HAL(Hardware Abstraction Layer) 계층을 포함하며 일반모드 거리측정 기능을 갖는 IEEE 802.15.4a MAC(Medium Access Layer) 소프트 웨어 스택을 구현하였다. 개발된 IEEE 802.15.4a 스택 을 탑재한 센서노드를 활용해 테스트 네트워크를 구 축한 후 IEEE 802.15.4a의 RF 칩의 하드웨어에서 제 공하는 실시간 거리측정의 정확도가 실 환경에서도 최대한 활용될 수 있는지를 실험을 통해 검증하였다. 향후 개발된 소프트웨어 스택에 SDS-TWR의 신속모 드 기능을 추가하여 보다 실용적인 버전으로 확장할 필요가 있다. 아울러 개발된 소프트웨어 스택의 거리 측정 성능의 질을 판정할 수 있도록 나노트론 사의 개발보드와 소프트웨어 환경으로 동일한 참조 네트워 크를 구성해서 거리측정 성능을 비교할 계획이다.

\section{참고문헌}

[1] S.-K. Park and Y.-S. Suh, "Pedestrian navigation system using inertial sensors and vision", Trans. KIEE, vol. 59, No. 11, 2010 
[2] J.-H. Boo, "Motion tracking system using inertial sensors", M.S. Dissertation, Department of Ulsan University, Ulsan, 2011.

[3] H.S. Ahn and W. Yu, "Chapter 14: Indoor localization techniques based on wireless sensor networks," in "Mobile Robots - State of the Art in Land, Sea, Air, and Collaborative Missions", I-Tech, 2008.

[4] H.S. Ahn, H. Hur, W.-S. Choi, "One-way ranging technique for CSS-based indoor localization," Proc. of the IEEE INDIN, Daejeon, Korea, pp. 1513-1518, 2008.

[5] J.-S. Kim, J.-U. Yang, and S.-H. Yang, " study on the location awareness system using TOA (time of arrival) of CSS (chirp spread spectrum) algorithm", The Journal of The Korea Institute of Intelligent Transport Systems, vol. 7, no. 2, pp. 13-25, 2008.

[6] Hanback Electronics, "HBE-Ubi-nanoLOC Ubiquitous Sensor Network," 2009.

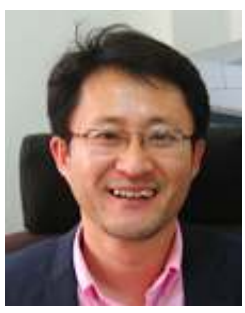

유 준 혁 (Joonhyuk Yoo)

- 정회원

• 포항공과대학교 전자전기공학과 공학사

• 포항공과대학교 전자전기공학과 공학석사

- 미국 매릴랜드대학교 컴퓨터공학과 공학박사

- 대구대학교 정보통신대학 정보통신공학부 임베디드 시스템전공 교수

- 관심분야 : 임베디드 소프트웨어, 컴퓨터구조, 사이 버-물리 시스템

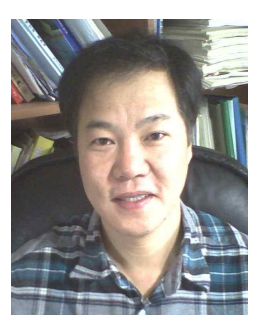

김 희 철 (Hiechelo $\mathrm{Kim})$

- 정회원

- 연세대학교 전자공학과 학사

- 남가주대학교 컴퓨터공학과 석사

- 남가주대학교 컴퓨터공학과 박사

- 대구대학교 정보통신대학 임베디드시스템공학과 교수

- 관심분야 : 임베디드 운영체제, 무선센서네트워크

논 문 접 수 일 : 2013년 09월 09일 1차수정 완료일 : 2013년 09월 25일 2차수정 완료일 : 2013년 10월 17일 게 재 확 정 일 : 2013년 10월 21일 